\title{
Anaesthetic management of a patient with myasthenia gravis for abdominal surgery using sugammadex
}

Alina Rudzka-Nowak, Mariusz Piechota

Department of Anaesthesiology and Intensive Therapy, Military Medical Academy University Hospital in Lodz, Medical University of Lodz, Poland

Submitted: 9 July 2010

Accepted: 13 August 2010

Arch Med Sci 2011; 7, 2: 361-364

DOI: 10.5114/aoms.2011.22094

Copyright (c) 2011 Termedia \& Banach

\section{Abstract}

We report a case of a patient with tumor of the caecum with coexistent myasthenia gravis (a form according to Osserman II A), requiring general anesthesia for abdominal surgery. To reverse the neuromuscular block induced by vecuronium was used sugammadex.

Key words: sugammadex, myasthenia gravis, neuromuscular monitoring, vecuronium.

\section{Introduction}

Myasthenia gravis (MG) is a chronic autoimmune neuromuscular disease manifesting with weakness and fatigue of skeletal muscles after physical exercise, with a tendency to subside after periods of rest and typically after taking anticholinesterase medication. Myasthenia gravis is characterized by autoantibody attack of acetylcholine receptors at the motor end plate of striated muscles, which results in variable muscle weakness made worse by exercise [1]. Myasthenia gravis occurs in about 3-7 people per 100,000 - usually only sporadically.

The pathomechanism of the disease is associated with the formation of autoimmune complexes in acetylcholine receptors on the postsynaptic membrane of the neuromuscular junction. There is a close relationship between immune processes accompanying myasthenia gravis and the thymus, which has been found to contain production sites of B-cells synthesizing anti-receptor antibodies [2].

Of major clinical importance is the classification of myasthenia gravis developed by Osserman [3]. In 1958, Osserman proposed placing patients with myasthenia gravis in five groups: I - localized (ocular), II - generalized (mild or moderate), III - acute fulminating, IV - late severe, and V - muscle atrophy. Later, Osserman divided group II into the subclassification: A (mild) and $B$ (moderate). Various modified criteria have been suggested over the years. This classification allows one to grade the disease and assess the perioperative risk and possible complications.

Myasthenic crisis may be defined as respiratory failure or delayed postoperative extubation for more than $24 \mathrm{~h}$ resulting from myasthenic weakness. Myasthenic crisis results from weakness of upper airway muscles leading to obstruction and aspiration, weakness of respiratory muscles leading to reduced tidal volumes, or from weakness of both muscle groups.

\author{
Corresponding author: \\ Mariusz Piechota, MD, PhD \\ Department of Anaesthesiology \\ and Intensive Therapy \\ Military Medical Academy \\ University Hospital in Lodz \\ 1 Hallera $\mathrm{Sq}$ \\ 90-647 Lodz, Poland \\ Phone: +48 426393070 \\ Fax: +48426393097 \\ E-mail: \\ mariuszpiechota@poczta.onet.pl
}


Over the last four decades, the prognosis for myasthenic crisis has dramatically improved from a mortality rate of $75 \%$ to the current rate of less than 5\%. Common precipitating factors for myasthenic crisis include respiratory infections, aspiration, sepsis, surgical procedures, rapid tapering of immune modulation, beginning treatment with corticosteroids, exposure to drugs that may increase myasthenic weakness, and pregnancy [4].

Surgery and anaesthesia in myasthenic gravis patients are associated with an increased risk of death and severe complications. The risk is mainly related to a markedly higher sensitivity to muscle relaxants observed in this group of patients, even in periods of complete remission [5]. Myasthenia patients often require prolonged ventilation in the ICU setting $[3,6,7]$. A significant, though less common, perioperative risk in myasthenic patients is cholinergic crisis.

The most proper approach during anaesthesia in patients with myasthenia gravis is to apply deep inhalational anaesthesia without muscle relaxing agents. However, in abdominal and colorectal surgery sometimes it is necessary to use muscle relaxants in order to improve operating conditions - to have better access to the operational field.

The safety of using muscle relaxing agents in patients with myasthenia gravis undergoing major surgical procedures has so far been assessed as insufficient. Consequently, many anaesthesiologists routinely decided against using muscle relaxants in such clinical cases. The situation may change with sugammadex, a novel agent recently introduced into clinical practice. Sugammadex (ORG 25969) is a modified $\gamma$-cyclodextrin [8-11] (su refers to sugar and gammadex refers to the structural molecule $\gamma$-cyclodextrin). Unterbuchner et al. report the successful use of the modified cyclodextrin sugammadex in a myasthenic patient to reverse a vecuronium-induced deep level of neuromuscular block [12].

\section{Case report}

An 85-year-old white male patient was scheduled for right-sided hemicolectomy due to caecal tumour. At the time of admission to the Department of General and Colorectal Surgery, the patient had no complaints.

The patient had been treated for myasthenia gravis (Osserman stage Ila) since 2004. He had a number of operations previously: appendectomy (1940), left inguinal hernioplasty (1995), right inguinal hernioplasty (2003) (reoperation in 2005 due to wound dehiscence). He received the following medications: Mestinon (Pyridostigmini bromidum) $(3 \times 1$ tabl), Metazydyna (Trimetazidini dihydrochloridum), Vicebrol (Vinpocetinum), Zoxon (Doxazosini mesilas), Penestan (Finasteridum). The patient was in the optimum condition for surgery, with no absolute neurological contraindications to the operation and no abnormalities identified in laboratory tests.

The patient was scheduled for surgery under general endotracheal anaesthesia (ASA class III). The patient received no premedication due to existing contraindications to benzodiazepines. Induction of general anaesthesia was obtained with propofol at $2 \mathrm{mg} / \mathrm{kg}$. The patient was intubated with spontaneous respiration. Intubation was uncomplicated. Immediately after the intubation, remifentanil was given in a continuous intravenous infusion of $50-150 \mu \mathrm{g} / \mathrm{h}$. General inhalation endotracheal anaesthesia was performed according to procedures in place, using sevoflurane in an air/oxygen mixture with low gas flow. During anaesthesia, the patient's mechanical ventilation parameters were adjusted on the basis of standard anaesthesiological evaluation. Doses of anaesthetic agents were modified according to the clinical assessment of the depth of anaesthesia. Neuromuscular transmission was blocked with vecuronium administered at fractional doses of $1 \mathrm{mg}$ until the required degree of relaxation (with nerve stimulation monitoring performed by the Datex-Ohmeda, mode TOF). Maintenance doses of $1 \mathrm{mg}(0.015 \mathrm{mg} / \mathrm{kg}$ body weight) were administered every $50 \mathrm{~min}$. Overall, $5 \mathrm{mg}$ of vecuronium was administered during the 3-hour surgery. The management described above resulted in excellent circulatory stabilization (Table I).

Table I. Data of cardiovascular parameters during anaesthesia

\begin{tabular}{|lcc|}
\hline Parameters & Heart rate [beats/min] & Non-invasive blood pressure [mmHg] \\
\hline Induction & 96 & $136 / 80$ \\
\hline Start of the operation & 90 & $110 / 58$ \\
\hline $\begin{array}{l}\text { Every } 15 \text { min during } 3 \mathrm{~h} \\
\text { of the operation }\end{array}$ & $88 ; 86 ; 80 ; 75 ; 76 ; 78 ;$ \\
& $76 ; 72 ; 70 ; 70 ; 72$ & $110 / 60 ; 112 / 59 ; 110 / 60 ; 100 / 58 ;$ \\
& & $100 / 60 ; 100 / 60 ; 102 / 62 ; 100 / 62 ;$ \\
End of the operation & 72 & $110 / 58 ; 112 / 62 ; 112 / 60$ \\
\hline Extubation & 72 & $112 / 68$ \\
\hline
\end{tabular}


The patient underwent right-sided hemicolectomy due to a caecal tumour with a diameter of approx. $8 \mathrm{~mm}$ infiltrating the mesentery.

Emergence from anaesthesia was initiated at the time of placement of the final skin suture. Sugammadex (Bridion) in a $3 \mathrm{mg} / \mathrm{kg}$ bolus was administered to reverse the neuromuscular block. Neuromuscular block reversal was monitored by the Datex-Ohmeda monitor simulation and clinical signs. Five min after Bridion administration, the patient regained efficient pulmonary respiration and full logical contact was re-established. The patient was extubated 6 min after Bridion administration.

Upon emergence from anaesthesia and extubation, the patient was transferred to the recovery room of the Anaesthesia and Intensive Care Department. Full verbal contact and recovery of consciousness with the patient was maintained at the time of transfer to the recovery room. The patient's respiratory function and circulatory status were uncompromised. Postoperative analgesia was provided with remifentanil administered in a continuous infusion. The patient stayed in the recovery room of the Anaesthesia and Intensive Care Department for $20 \mathrm{~h}$ before being transferred to the Department of General and Colorectal Surgery. During 6 days postoperative stay in the Department of General and Colorectal Surgery, the patient received $100 \mathrm{mg}$ of Ketoprofenum intravenously three times per day. The patient was discharged on the $7^{\text {th }}$ postoperative day.

\section{Discussion}

Myasthenia gravis patients, particularly those undergoing major surgery and/or suffering from concomitant disorders, require special individual management in preparation for surgery [5], appropriate selection and administration of anaesthesia, and close monitoring postoperatively [13]. This also applies to other groups of patients with nervous system disorders including myopathies and other muscular diseases [14, 15].

Sensitivity to non-depolarizing neuromuscular blocking drugs is known to vary greatly between myasthenic patients. Several studies using a cumulative technique have shown the ED95 for vecuronium to range from $6 \mu \mathrm{g} / \mathrm{kg}$ to $44 \mu \mathrm{g} / \mathrm{kg}$. Ocular myasthenic patients were less sensitive to vecuronium than generalized myasthenic patients. During general anaesthesia, neuromuscular monitoring is essential to avoid problems of prolonged neuromuscular block in myasthenic patients. Vecuronium is a muscle relaxing agent usually applied during the surgery in our hospital.

Epidural anaesthesia is less controllable in cases of intraoperative haemorrhage. Epidural anaesthesia causes sympathetic blockade with blood vessel dilation and venous stasis; thus hypovolaemia as a result of a haemorrhage is more difficult to compensate than general endotracheal anaesthesia, especially in elderly patients.

The best way of preparing a patient for a surgical procedure is to recognize and understand both the underlying medical condition and coexisting diseases. Proper awareness of these makes it possible to arrange individual pre-, peri- and postoperative management. The procedure was followed in the case reported here. Each stage of perioperative care was thoroughly analysed and planned.

Currently used neuromuscular transmission blockers are considered safe, with the recovery of normal muscle function occurring after a period specific to each drug. Acetylcholinesterase inhibitors are used to accelerate the recovery of normal neuromuscular transmission following administration of non-depolarizing neuromuscular blockers. The time of administration of these agents is of major importance, since administered prematurely, they can paradoxically result in neuromuscular block reversal. As many as $60 \%$ of patients undergoing surgery under general anaesthesia are believed to be likely to experience problems with residual activity of skeletal muscle relaxants (PORC - postoperative residual curarization) [16-18]. The launch of sugammadex, an agent reversing neuromuscular block induced by steroid muscle relaxants, holds out hope to steadily reduce the incidence of PORC [19]. Unquestionable benefits of the drug include: rapid neuromuscular block reversal regardless of its depth [20-22], documented drug safety and tolerance [2325], and - above all - an innovative mechanism of action [25]. All the beneficial qualities of sugammadex offer the possibility for using the drug in patients who are expected to have problems with proper ventilation and gas exchange.

In the case described here, sugammadex made it possible to perform a safe general anaesthesia procedure with skeletal muscle relaxants without prolonging mechanical ventilation. The medical literature contains isolated reports on the use of sugammadex (with success) in patients with myasthenia and other muscular dystrophies [12].

The authors of this report believe that sugammadex as an agent used for muscle relaxation in delivering anaesthesia to MG patients during abdominal surgery could one day be recognized as the gold standard. Sugammadex, used in combination with objective neuromuscular monitoring, can be applied to reverse vecuroniuminduced neuromuscular blockade in patients with myasthenia gravis.

\section{Acknowledgments}

Department/institution to which the work is attributed: Department of Anaesthesiology and 
Intensive Therapy, Military Medical Academy University Hospital in Lodz. Sources of financial support for the work: Military Medical Academy University Hospital in Lodz

\section{References}

1. Conti-Fine BM, Milani M, Kaminski HJ. Myasthenia gravis: past, present, and future. J Clin Invest 2006; 116: 2843-54

2. Bachmann K, Burkhardt D, Schreiter I, et al. Thymectomy is more effective than conservative treatment for myasthenia gravis regarding outcome and clinical improvement. Surgery 2009; 145: 392-8.

3. Mincewicz G, Aloszko A, Nyka W, Bilińska M, Krzykowski G, Nyka WM. The comparison of selected spirometric parameters with functional muscles exercise evaluation in patients with myasthenia [Polish]. Pol Merkur Lek 2007; 22: 177-81.

4. Juel VC. Myasthenia gravis: management of myasthenic crisis and perioperative care. Semin Neurol 2004; 24: 75-81.

5. Dillon FX. Anesthesia issues in the perioperative management of myasthenia gravis. Semin Neurol 2004; 24: 83-94.

6. Haroun-Bizri S, Maalouli J, Deeb P, Baraka A. Anesthetic management for a patient with myasthenia gravis undergoing coronary artery bypass graft. Middle East J Anesthesiol 2003; 17: 299-305.

7. Heliopoulos I, Patlakas G, Vadikolias K, et al. Maximal voluntary ventilation in myasthenia gravis. Muscle Nerve 2003; 27: 715-9.

8. Bom A, Bradley M, Cameron K, et al. A novel concept of reversing neuromuscular block: chemical encapsulation of rocuronium bromide by a cyclodextrin-based synthetic host. Angew Chem Int Ed Engl 2002; 41: 266-70.

9. Adam JM, Bennett DJ, Bom A, et al. Cyclodextrin-derived host molecules as reversal agents for the neuromuscular blocker rocuronium bromide: synthesis and structureactivity relationships. J Med Chem 2002; 45: 1806-16.

10. Tarver GJ, Grove SJ, Buchanan K, et al. 2-O-substituted cyclodextrins as reversal agents for the neuromuscular blocker rocuronium bromide. Bioorg Med Chem 2002; 10 : 1819-27.

11. Cameron KS, Clark JK, Cooper A, et al. Modified gammacyclodextrins and their rocuronium complexes. Org Lett 2002; 4: 3403-6.

12. Unterbuchner C, Fink $H$, Blobner $M$. The use of sugammadex in a patient with myasthenia gravis. Anaesthesia 2010; 65: 302-5.

13. Cardone A, Congedo E, Aceto $P$, et al. Perioperative evaluation of myasthenia gravis. Ann Ital Chir 2007; 78: 359-65.

14. Cameron MH, Klein EL. Screening for medical diseasenervous system disorders. J Hand Ther 2010; 23: 158-71.

15. Blobner M, Mann R. Anesthesia in patients with myasthenia gravis. Anaesthesist 2001; 50: 484-93.

16. Viby-Mogensen J. Postoperative residual curarization and evidence-based anaesthesia. Br J Anaesth 2000; 84: 301-3.

17. McCaul C, Tobin E, Boylan JF, McShane AJ. Atracurium is associated with postoperative residual curarization Br J Anaesth 2002; 89: 766-9.

18. Debaene B, Plaud B, Dilly MP, Donati F. Residual paralysis in the PACU after a single intubating dose of nondepolarizing muscle relaxant with an intermediate duration of action. Anesthesiology 2003; 98: 1042-8.
19. Flockton EA, Mastronardi P, Hunter JM, et al. Reversal of rocuronium-induced neuromuscular block with sugammadex is faster than reversal of cisatracuriuminduced block with neostigmine. Br J Anaesth 2008; 100: 622-30.

20. Khuenl-Brady KS, Wattwil M, Vanacker BF, Lora-Tamayo J, Rietbergen H, Alvarez-Gómez JA. Sugammadex provides faster reversal of vecuronium-induced neuromuscular blockade compared with neostigmine: a multicenter, randomized, controlled trial. Anesth Analg 2010; 110: 64-73.

21. White PF, Tufanogullari B, Sacan O, et al. The effect of residual neuromuscular blockade on the speed of reversal with sugammadex. Anesth Analg 2009; 108: 846-51.

22. Duvaldestin P, Kuizenga K, Saldien V, et al. A randomized, dose-response study of sugammadex given for the reversal of deep rocuronium- or vecuronium-induced neuromuscular blockade under sevoflurane anesthesia. Anesth Analg 2010; 110: 74-82.

23. Dahl V, Pendeville PE, Hollmann MW, Heier T, Abels EA, Blobner M. Safety and efficacy of sugammadex for the reversal of rocuronium-induced neuromuscular blockade in cardiac patients undergoing noncardiac surgery. Eur J Anaesthesiol 2009; 26: 874-84.

24. Weaver JM. New drugs on the horizon may improve the quality and safety of anesthesia. Anesth Prog 2008; 55 : 27-8.

25. Naguib M. Sugammadex: another milestone in clinical neuromuscular pharmacology. Anesth Analg 2007; 104: $575-81$ 